\title{
READERS
Insight
}

\author{
Journal of Research in Psychology (JRP) \\ www. readersinsight.net/jrp \\ ISSN: 2664-9500 (Online) \\ ISSN: 2664-9497 (Print)
}

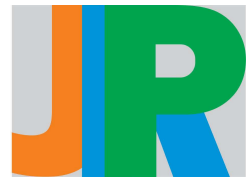

\section{Private Preschool Teachers' Competencies in Early Identification of Children at Risk of Learning Disabilities.}

\author{
Norzah Md.Yunus ${ }^{1 *}$, Suziyani Mohamed ${ }^{2}$ \\ Faculty of Education Universiti Kebangsaan Malaysia 43600 Selangor Malaysia.
}

norzah@gmail.com

\begin{abstract}
Not only education is important in developing one's intellectual and personal quality, but also an influential factor in seeking employment. Therefore, education is even more important for disabled individuals, as it enables them to read and write, communicate, make decisions and most importantly be employed. However, Dr Mullai Ramaiah stated that the current Malaysian education system does not only lack in early screening, but also teachers who are equipped to teach and handle children with special needs (Arukesamy, 2017). Therefore, this current study intends to investigate the competency of preschool teachers in identifying children who are at risk of any learning disabilities (LD). This was done by administering a questionnaire survey to examine teachers' knowledge of some common learning disabilities that usually affects preschool children. In this research, the relationship between teachers' competency and teacher's education level has been investigated. Findings from the data analysis indicated that the level of teacher's competency in identifying children at risk is relatively low. It was revealed, a majority of general preschool teachers do not have any knowledge or acquired minimal knowledge in identifying children who are at risk of an LD. Findings also show that there was a significant difference in competencies between teachers of different levels of education. Finally, it was found teachers' experience does not contribute to their knowledge in identifying children at risk of LD.
\end{abstract}

Keywords: preschool, teacher competencies, early identification, learning disabilities
Article Information:

Received: 25 Mar 2019

Revised: $\quad 15^{\text {th }}$, Aug 2019

Accepted: $\quad 5^{\text {th }}$, Sep 2018

\section{Introduction}

World Health Organisation (WHO) and the World Bank estimated that around one billion individuals experience some form of disability. About 93 to 150 million of those are children. Furthermore, these children are 10 times less likely to attend school than other children and even if they do, they are going to be separated from the other children (Ravassard, 2018).

In Malaysia specifically, more than 18,000 children are registered as having learning disabilities like attention deficit hyperactivity disorder (ADHD), autism and dyslexia (UNICEF Malaysia, 2014)

Categories of children with LD who are under the responsibility of Malaysia's Ministry of Education are as follows, Down Syndrome, mild autism, Attention Deficit Hyperactivity Disorder (ADHD), minimum retardation and specific learning difficulties (for example dyslexia) (Ministry of Education, 2013).

It appeared to the researcher that the nation lacks the facility and the skilled manpower to promote inclusivity for children with learning disabilities. This can be clearly seen through the 2014 Children with Disabilities in Malaysia report by UNICEF, which reports there is only one school among 28 national special education schools to cater to the 18,000 previously mentioned children in Malaysia. This ultimately caused many parents choose to place their children with learning disabilities in private schools run by NGOs and faith-based organizations instead.

The UNICEF report also highlighted several issues with the Malaysian national special needs education program, including a shortage of qualified teachers, as well as the lack of a tailored curriculum for specific learning disabilities.

These matters were further supported by Dr. Mullai Ramaiah, The President of the National Organisation for Dyslexia who stated that the current Malaysian education system does not only lack in early screening, but also teachers who are equipped to teach and handle children with special needs (Arukesamy, 2017).

This article is a direct result from the desire to investigate the extent of lack of skilled manpower in some of the private kindergartens located in urban areas of Selangor, Kuala Lumpur and Federal Territory of Putrajaya. This research is particularly interested to investigate whether experience and academic background of educator plays a role in the detection of children who are at risk of LD. Specifically, the study addresses the following research questions:

1. What is the level of current teachers' competency in identifying children who are at risk of a learning disability?

2. How teachers' education level affects their competency in identifying children at risk of a learning disability? 
3. How teachers' experience affects their competency in identifying children at risk of a learning disability?

\section{Literature review}

\section{Learning Disabilities}

According to Hammill et al. (1987), learning disabilities, LD is a generic term that describes a heterogeneous group of disorders shown by apparent difficulties in the acquisition and use of listening, speaking, reading, writing, reasoning or mathematical abilities. Another definition by Santrock (2006), explains, children with LD are as such, (i) are of normal intelligence or above, (ii) have difficulty in at least one academic area and usually several, and (iii) have no other diagnosed problem or disorder, such as mental retardation, that is causing the difficulty.

The following section discusses issues related to competency of teachers' in identifying children at risk of learning disabilities. Issues of Learning Disabilities across the Globe

Findings of a study carried out by Alahmadi and El-Keshky (2018) to assess primary school teachers' knowledge in regards to special learning disabilities in Kingdom of Saudi Arabia, depicts that a majority of primary school teachers have average knowledge about specific learning disabilities. Additionally, the study correspondingly shows a significant relationship between levels of knowledge and socio-demographic variables. Using a descriptive and quantitative approaches, the investigation was carried out on 902 private primary and public school teachers from 78 schools across different regions of Saudi Arabia.

A study that was carried out in Dodoma, Tanzania to research on teachers' awareness of students with LD in public primary school show that only a few teachers were aware of their presence. Although the number seems considerably low, the researchers state that this is higher than $10-12 \%$ portrayed in the existing literature. Kafonogo and Bali (2013) carried out this research on 200 participants, 100 teachers, and 100 pupils, using exploratory research design.

Review of previous studies as above shows that a large majority of research on teacher competencies in identifying children at risk of learning disabilities was carried out on primary school students instead of kindergarten students. This could be as Hebbeler and Spiker (2016) state that young children with difficulties are difficult to assess. On top of that, based on previous literature too, researcher found that teachers' abilities across the globe in identifying students with LD varies from limited to average.

\section{The Malaysian Scene}

According to UNICEF Malaysia (2014), more than 18,000 children in the country are registered as having learning disabilities like attention deficit hyperactivity disorder (ADHD), autism and dyslexia. In an issue brief by UNICEF Malaysia in 2014, it stated that among the responsibility of Ministry of Education of Malaysia (MOE) to children with disabilities in the country are; "to manage the training of teachers and teaching resources for special needs education, manage early intervention for children with disabilities at pre-school level and from $0-6$ years of age at Special Education Service Centres and register and monitor private special education institutions at pre-school, primary and secondary level including teaching curricula and infrastructure"

In 2016, the then Deputy Education Minister, Datuk P. Kamalanathan stated that mainstream teachers will be trained and provided with skills to enable them to identify students with special needs. This is because although there are some teachers who want to help these students but they lack the knowledge on how to deal with them (Erda Kursyiah, 2016).
Also in the same year, the then Universiti Pendidikan Sultan Idris's (UPSI) deputy vice-chancellor for student affairs, Assoc Prof Datuk Dr Junaidy Abu Bakar said there was a current shortage of special education teachers at regular schools (Erda Kursyiah, 2016).

Despite such comprehensive statements by policymakers, in 2018, president of Pertubuhan Sokongan Ibubapa Dyslexia Malaysia (PSIDM), Ahmad Fitri Isahak said there are more primary and secondary schools' teachers that needed to be trained to be able to recognize the symptoms of learning disability (Mariswanie, 2018). Additionally, Dyslexia Malaysia Association (DMA), president Sariah Amirin said it was imperative that children with dyslexia are properly diagnosed and exposed to appropriate teaching methods especially during the early stages of schooling. This early intervention, Sariah added, is vital so the child is able to deal with his learning disability at an earlier age (Mariswanie, 2018).

These statements by policymakers indicate to the researcher that the country still lacks competent teachers in identifying students at risk or with learning disabilities (Erda Kursyiah, 2016 and Mariswanie, 2018). Besides that, early intervention of students at risk of learning disabilities is crucial for the student progress and education development (MOE, 2014 and Mariswanie, 2018)

\section{Similar Studies}

The researcher had found several related studies related to the current research. It is found, worldwide, many research in regards to students with LD revolves around knowledge and attitude of teachers regarding LD instead of teachers' ability or competency in the detection of students at risks of LD.

A study of teachers' knowledge in regards of LD, done on 200 primary school teachers from 16 schools in Bangalore, India, shows both teachers' education level and their years of teaching experience are significant contributors to teachers' knowledge in regards to LD (Shari and Vranda, 2015).

These findings were very different from Khalil and Jenahi (2019) research which showed teachers' knowledge of a specific disorder (Attention Deficit Hyperactivity Disorder, ADHD) was not significantly correlated with their years of experience and level of education (qualification).

However, research done by Alahmadi and El Keshky (2019) on primary school teachers' knowledge of specific LDs in Kingdom of Saudia Arabia indicated a different finding from both previously mentioned research. The findings show education level of teacher is a significant contributor to their knowledge on specific LDs. Meanwhile, the duration of teaching experience was found to be an insignificant variable, on teachers' knowledge of specific LDs.

In a study similar to this research by Kakabaree, Arjmandnia and Afrooz (2012), a study to investigate primary teachers' awareness and capability to identify students with learning disability in Kermanshah, Iran, it was found that more than 90 percent of teachers had not the acceptable ability in identifying students with learning disorders. The study carried out on 291 primary teachers indicated there were significant differences between gender and qualification levels of teacher with knowledge of LD.

In a study to examine teachers' attitudes in regards to the inclusion of students with special educational needs and how these attitudes are influenced by their self-efficacy perceptions (Tsakiridou and Polyzopoulou, 2014), it was found that teaching experience is a significant variable on teachers' self-efficacy belief. They further explain that teachers' prior teaching experience offers them a greater 
sense of overall effectiveness, a sense of efficacy in classroom management and are successful in the use of educational strategies.

Tsakiridou and Polyzopoulou findings were very different from older studies that had been carried out by Leite (2012) and Siderides, Antoniou, and Padeliadadu (2008). Leite and Siderides, Anotniou and Padeliadadu research which focused on teachers' ability on knowledge and detection of students with LD (with Leite's study being focused more on Dyslexia) indicated that experience does not have a significant role in this matter.

In conclusion, previous studies show a diversified patterns of findings regarding knowledge linked to LD and detection of students with LD. Some research, such as Shari and Vranda's (2015), indicates that teachers' qualification and years of working experience contribute to teachers' knowledge regarding LD. On the other hand, for research like Khalil and Jenahi's (2019) these two variables are found not to be linked to teachers' knowledge of LD.

Meanwhile, for Alahmadi \& El Keshky (2019) and Kakabaree, Arjmandnia \& Afrooz (2012) investigations, only qualification levels of teacher and not their working experience was found to be related with their knowledge of LD.

Based on Tsakiridou and Polyzopoulou, (2014) findings on the other hand, teachers' working experience played a significant role in their abilities dealing with LD students. Meanwhile, Leite (2012) and Siderides, Antoniou and Padeliadadu (2008) study found that working experience does not play a significant role in their knowledge and detection of LD students.

\section{Conceptual Framework}

The conceptual framework (Figure 2) of this study consists of two sub-constructs, the understanding of teachers' competencies and children who are at risk. Understanding teachers' competencies include the definition of teachers' competencies, teachers' role in identifying children at risk and the model of teacher competencies (Figure 1). While the understanding of children at risk discusses the definition of children at risk, definition of learning disabilities, types of learning disabilities and the importance of early identification of children at risk.

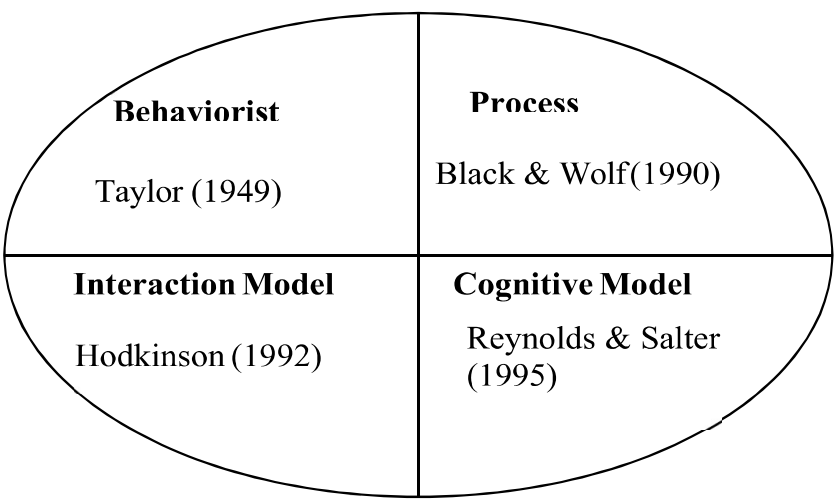

Fig. 1. Model of Competency

There were four models of competency summarized from the study done by Cheng and Cheung (2004) shown in Figure 1 above. The first model was the Behaviourist Approach from Taylor back in 1949. This approach results from a task analysis of a teacher by dividing it into basic elements. The second approach was Process Model by Black and Wolf in 1990. The functional approach used in this model, where the experience and knowledge is an essential element in teacher competency. The third competency approach, Interactive Model by Hodkinson in 1992 which emphasized on the importance of communication between humans and communication between human and environment. Lastly, Cognitive Model developed by Reynolds and
Salter in 1995 discuss on the importance of teachers' cognitive knowledge. The entire four models complement each other in providing the insight of teachers' competencies.

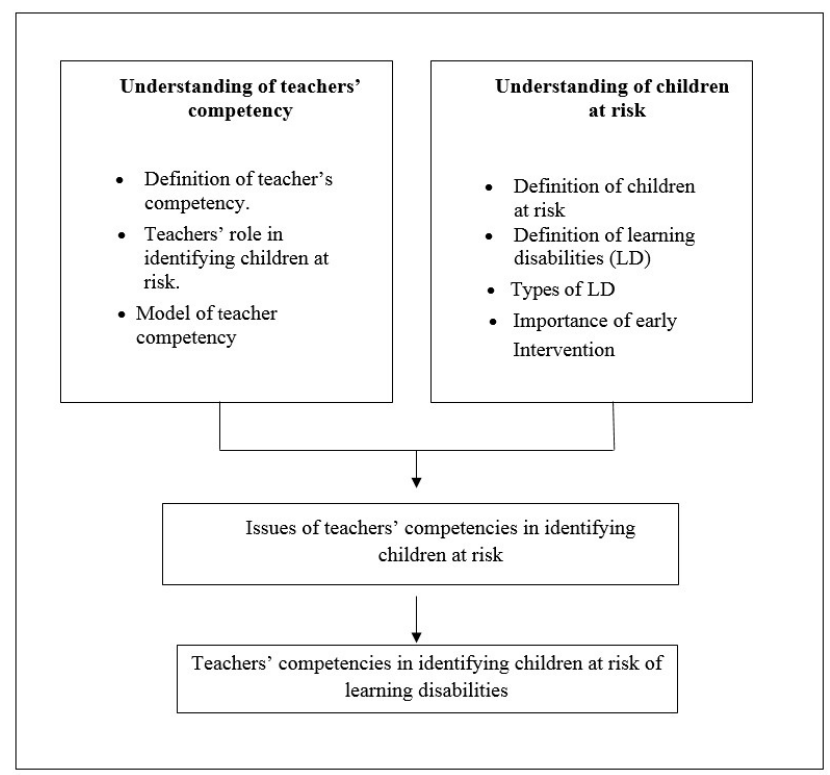

Fig. 2. Conceptual Framework

\section{Methodology}

A survey quantitative research design has been carried out on the participants of the study. This particular research design has been selected as the researcher believes it is the most suitable to this study, as, as stated by Fraenkel and Wallen (2011) it is designed to gather information from a group of sample to describe a certain characteristic such as capabilities, views, attitudes, beliefs or knowledge of a population, (the group in this research being a group of kindergarten teachers).

\section{Sample Population}

The convenience sampling approach was used as it is a faster and easier approach for data

collection. The choice of schools also depended on the willingness of the principals to allow their students to be involved in the study.

The participants of this study were 93 female teachers from 12 preschools located in selected urban areas in Kuala Lumpur, Selangor and suburban areas in Federal Territory Putrajaya. The teachers were of various positions and races. Please refer to the findings section for the actual distribution. Data collection was carried out in a duration of 6 months from August 2018 until January 2019.

\section{Research \Instrument}

The questionnaire used for this present study had been adapted and modified from a previous study done by Cavazos (2002). The reason behind this decision is, the study that was done by Cavazos (2002) focused more on communication disorders instead of LD (which is the focus of this study). The questionnaire distributed consisted of 2 parts. The first part consisted of 2 sections, Section A and Section B. Section A (Demographics of Respondent Form) consists of a form to elicit their personal background information.

Section B (Personal Experience with Disabilities) consists of questions on participants' personal experience on disabilities as well as their perception of their own knowledge on different types of disabilities. Some examples of questions that can be found in this 
section are: Does any of your child have any disability?, does anyone in your immediate family have any disability, do you know anyone with any disability?

Besides that, this section also required participants to self-evaluate their ability in recognizing children's learning disability of their choice (learning disabilities that have been listed in the questionnaire).

The second part too consisted of 2 sections, Section $\mathrm{C}$ and Section D. This part of the questionnaire was specifically designed to collect data on teachers' current general knowledge on characteristics of the listed learning disabilities.

Section $\mathrm{C}$ is an open-ended section where the participants are given 3 scenarios and required to state if the child in the given scenarios is affected by any LD. For each of the scenario, participants are also required to write what they would like to advise the parents in an attempt to address the condition of the child.

Finally, the last section, Section D, is a close-ended section where it tested respondents' knowledge in identifying children who might be at risks of learning disabilities. It consists of twenty common characteristics faced by preschool children. Participants were required to group the characteristics into six groups (Autism, Asperger, Dyslexia, Dyscalculia, ADHD and ADD) by putting a

cross (x) on the correct disability box for every symptom faced by the children.

\section{Research Procedure}

The following procedures were followed:

1. Participants were first informed about the confidentiality of the survey. Only individuals who agree to participate in the study were given the survey form to be filled.

2. Participants were informed that they were required to complete the questionnaire based on their current knowledge. They were prohibited to look for answers from external resources or by conversing with other individuals while partaking in the study. If the participants are unsure about the questionnaire, the participants are required to ask the researcher herself.

3. The questionnaires were administered and collected on the same day to ensure a $100 \%$ return rate and to avoid participants to look into external resources. Overall, each participant generally took about 15-20 minutes to fill up the questionnaire.

\section{Data Analysis}

All answers were inspected for missing data prior to data analysis. Data between question 7 of Section B, Section C, and Section $\mathrm{D}$ were being analyzed for consistency of the respondent in providing his/her answers. Data with inconsistent answer in these 3 sections will be rejected. Quantitative data from this questionnaire were coded and analyzed using Statistical Package for Social Science (SPSS) version 24. Data from part one, consisting of sections A and B were reported using descriptive statistics such as frequency, percentage, mean and standard deviation. Meanwhile, data from part 2 (Section C-openended questions) were analyzed using content analysis procedure. Lastly, data from part 2 (Section D, closed-ended questions) will be given a score in percentage based on the number of correct characteristics selected for each disability category. This final score will finally represent the teacher's competency in identifying children at risk for any learning difficulties. The inferential statistic was used to analyze data from this section of the questionnaire. The tests used include the Pearson coefficient correlation, T-test, and one-way ANOVA.

\section{Results}

The purpose of the study was to investigate the level of preschool teachers' competencies in early identification of children at risk of a learning disability. Among findings that were explored are participants' general competence in identifying children who are at risks of learning disabilities. Next, in this research, preschool teachers' competency was also examined in relation to their education level and duration of teaching experience.

\section{Findings And Discussion}

\section{Background Information of Participants}

There were 93 educators who completed and returned the questionnaires, yielding a response rate of $100 \%$. However, 3 sets of questionnaires from 3 participants were rejected as the questionnaires were not completed. Therefore, only 90 participants' questionnaires were used in the study.

i) Distribution of Gender

Analysis of the data indicates that the majority of the sample consisted were females. $92 \%$ of the samples $(n=83)$ were females and $8 \%(n=7)$ were males.

Table 1:

Distribution of gender $(n=90)$ )

\begin{tabular}{lllll}
\hline Variable & & Frequency & Percentage(\%) & $\begin{array}{l}\text { Cumulative } \\
\text { Percentage (\%) }\end{array}$ \\
\hline Gender & Male & 7 & 8 & 8 \\
& Female & 83 & 92 & 100 \\
\hline
\end{tabular}

\section{ii) Age of Participants}

Participants' age ranges from 18 years to above 50 years old $(\mathrm{M}=2.14, \mathrm{SD}=1.001)$. A majority of $36 \%$ of the participants were in the range of $30-39$ years old with $31 \%(n=32)$. The second highest age group reported were between 18 to 29 years old $(n=28)$, followed by $21 \%(\mathrm{n}=19)$ from the range 40 to 49 years and $12 \%(\mathrm{n}=11)$ were above 50 years old.

Table 2:

\begin{tabular}{lllll}
\multicolumn{2}{l}{$\begin{array}{l}\text { Participants age group }(n=90) \\
\text { Variable }\end{array}$} & & & \\
\hline Age & Frequency & Percentage (\%) & $\begin{array}{l}\text { Cumulative } \\
\text { Percentage (\%) }\end{array}$ \\
& 18-29 years old & 28 & 31 & 31 \\
& 30-39 years old & 32 & 36 & 37 \\
& 40-49 years & 19 & 21 & 88 \\
& Above 50 years & 11 & 12 & 100 \\
\hline
\end{tabular}

iii) Years of Teaching Experience

The teaching experience of the participant in this study range from zero experience to above 9 years $\mathrm{M}=2.68, \mathrm{SD}=1.216$ ), with a majority of $40 \%(n=36)$ participants experienced teacher who had been teaching for more than 9 years. This followed by $28 \%(n=25)$ who had experience range from 3 to 5 years. Twenty-two percent $(n=20)$ of the participants were considered novice teachers with teaching experience below 2 years, and the remaining $10 \%(\mathrm{n}=9)$ of the participant were range from 6 to 8 years of experience.

Table 3:

Participants' years of teaching experience $(n=90)$

\begin{tabular}{|c|c|c|c|c|}
\hline \multicolumn{2}{|l|}{ Variable } & Frequency & Percentage (\%) & $\begin{array}{l}\text { Cumulative } \\
\text { Percentage (\%) }\end{array}$ \\
\hline \multirow{5}{*}{$\begin{array}{l}\text { Duration of } \\
\text { experience }\end{array}$} & $0-2$ vears & 20 & 22 & 27 \\
\hline & $3-5$ years & 25 & 28 & 50 \\
\hline & $6-8$ years & 9 & 10 & 60 \\
\hline & Above 9 years & 36 & 40 & 100 \\
\hline & Total & 90 & 100 & \\
\hline
\end{tabular}


iv) Participants' job position

A majority of $66 \%$ of the participants were preschool teachers $(\mathrm{n}=$ 59), followed by $21 \%(\mathrm{n}=19)$ assistant teacher and $13 \%(\mathrm{n}=12)$ principals of the preschool.

Table 4:

Participants' job position ( $\mathrm{n}=90)$

\begin{tabular}{lllll}
\hline Variable & & Frequency & Percentage (\%) & Cumulative (\%) \\
\hline Job position & Principal & 12 & 13 & 13 \\
& Teacher & 59 & 66 & 79 \\
& Assistant teacher & 19 & 21 & 100
\end{tabular}

v) Teachers' education level

A majority of $61 \%(n=55)$ the respondent were non-graduates with minimal academic qualification of SPM or STPM. This was followed by $39 \%(n=35)$

Table 5: Teacher Education Level

Participants overall education level $(n=90)$

\begin{tabular}{lllll}
\hline Variable & Frequency & $\begin{array}{l}\text { Percentage } \\
(\%)\end{array}$ & $\begin{array}{l}\text { Cumulative } \\
\text { percentage (\%) }\end{array}$ \\
\hline Education level & Non-graduate & 55 & 61 & 61 \\
\hline & graduate & 35 & 39 & 100 \\
\hline
\end{tabular}

Participants were asked to indicate whether they have attended any course or training in early childhood education.

The analysis showed that $38 \%(n=34)$ of the participants did not attend any ECE courses or training while the balance $62 \% \quad(n=56)$ had attended training and courses or currently pursuing courses on early childhood education. Fourteen percent $(n=13)$ of the participants received in house training provided by the preschool. The balance $48 \%$ $(n=43)$ received early childhood education in various level $(16 \%$ Certificate, $16 \%$ Diploma, $11 \%$ Degree, $1 \%$ Master) and 4\% $(n=4)$ were currently pursuing Early Childhood Education (1\% Diploma, 1\% Degree and 2\% Master).

Table 6: Participant Early Childhood Level

Participants' Early Childhood Education level $(n=90)$

\begin{tabular}{llll}
\hline Variable & Frequency & Percentage (\%) \\
\hline Education level & No ECE qualification & 34 & 38 \\
& Certificate & 14 & 16 \\
& Diploma & 14 & 16 \\
& Degree & 10 & 11 \\
& Master & 1 & 1 \\
& In house training by preschool & 13 & 14 \\
& Currently pursuing Diploma in ECE & 1 & 1 \\
& Currently pursuing Degree in ECE & 1 & 1 \\
& Currently pursuing Master in ECE & 2 & 2 \\
& Total & 90 & 100 \\
\hline
\end{tabular}

vi) Teachers' Competency Level in Identifying Children at Risk of a Learning Disability

Participants' understanding of early identification of children at risk was explored via 20 items in Section D of the questionnaire. In order to identify further how competent were the participant, all the 20 characteristics were not arranged in sequence in section D. The participants needed to select the right characteristics for the following six disabilities (i) Autism, (ii) Dyslexia (iii) Dyscalculia (iv) ADHD, (v)ADD.

These responses were examined and analyzed. Each participant will be given a percentage score of correct answers for each group of disability as well as overall

score.
Table 7, summarised the participants' score of competency in identifying the characteristic of given learning disabilities. A majority of $47 \%(\mathrm{n}=24)$ of the participants achieved a score between $0 \%$ to $20 \%$. Followed by $19 \%(n=17)$ of the participants scored between $21 \%$ to $40 \%$. There were $17 \%(\mathrm{n}=15)$ participants who scored between $41 \%$ to $60 \%$, and $14 \%(n=13)$ were able to identify the given characteristic of the particular disability with a score between $61 \%$ to $80 \%$. However, only $3 \%(\mathrm{n}=3)$ participants managed to score above $81 \%$.

Table 7:

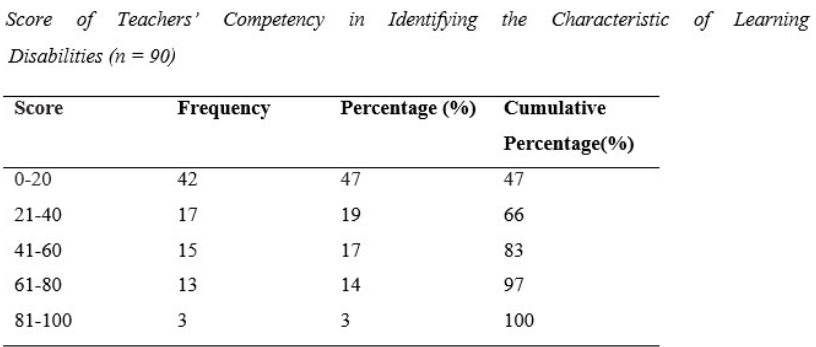

vii) The relationship between teachers' general education level and ability to identify children at risk of a learning disability

Research hypothesis stated that there would be no significant relationship between teachers' general education level and ability to identify children at risk.This analysis uses Pearson product-moment correlations to examine the possible relationship between teachers' general education level and ability to identify

children at risk. Analysis of data revealed that there was a significant relationship between teacher general education level $(\mathrm{M}=$ $1.47, \mathrm{SD}=.66)$ and their ability to identify children at risk $(\mathrm{M}=27.28$, $\mathrm{SD}=28.37)$. However, the both variable were inter-correlated moderately $(\mathrm{r}=.39, \mathrm{p}=.00)$ (please refer to Table 8$)$. The direction of the correlation was positive. This indicated that teacher who had higher general education level tend to display a higher ability to identify children at risk of LD graduate teachers in multiple fields.

Table 8:

Correlation between Preschool Teachers' General Education Level and Ability to Identify Children at Risk of a Learning Disability

\begin{tabular}{|c|c|c|c|c|c|c|}
\hline & \multicolumn{2}{|c|}{ General Education Level } & \multicolumn{4}{|c|}{$\begin{array}{l}\text { Ability to Identify } \\
\text { Children at Risk }\end{array}$} \\
\hline $\mathrm{N}$ & Mean & SD & Mean & SD & $\mathrm{r}$ & $p$ \\
\hline 90 & 1.47 & 0.66 & 27.28 & 28.37 & .39 & .00 \\
\hline
\end{tabular}

viii) A significant difference between teachers' ability to identify children at risk and difference in ECE educational attainment.Null hypothesis (Ho) stated that there will be no significant difference between teachers' ability to identify children at risk and difference in ECE education attainment. One-way analysis of variance (ANOVA) was conducted to evaluate if there is any significant difference between teachers' ability to identify children at risk of different ECE educational attainment. The independent variable, ECE educational attainment included: no ECE qualification, training given by kindergarten, ECE Certificate, Diploma, Degree, and Masters. The dependent variable was the total scores of teachers' ability to correctly identify the characteristic of children at risk of learning disabilities. The ANOVA was significant, $\mathrm{F}(5,84)=2.411, \mathrm{p}=.043$ (Please refer to Table 9). Therefore, null hypothesis was rejected. There are significant differences between teachers' ability to identify children at risk and difference in ECE educational attainment.

Table 9: 
One-Way ANOVA Test Comparing Teachers' Ability to Identify Children at Risk and Difference in ECE Educational Attainment

\begin{tabular}{|c|c|c|c|c|c|}
\hline & $\begin{array}{l}\text { Sum } \\
\text { Squares }\end{array}$ & df & Means Square & $\mathbf{F}$ & Sig. \\
\hline $\begin{array}{l}\text { Between } \\
\text { group }\end{array}$ & 9038.10 & 5 & 1797.61 & 2.41 & .043 \\
\hline $\begin{array}{l}\text { Within } \\
\text { group }\end{array}$ & 62450.01 & 84 & 745.55 & .39 & .00 \\
\hline Total & 71488.10 & 89 & & & \\
\hline
\end{tabular}

Table 10:

Means and Standard Deviations Comparing Preschool Teachers' Ability to Identify Children at Risk by ECE Level

\begin{tabular}{llll}
\hline & N & Means & SD \\
\hline No qualifications & 33 & 21.42 & 26.45 \\
Training by kindergarten & 13 & 22.85 & 30.43 \\
Certificate & 14 & 21.14 & 23.00 \\
Diploma & 16 & 32.44 & 27.49 \\
Degree & 10 & 37.80 & 30.41 \\
Master & 4 & 64.50 & 29.41 \\
Total & 90 & 27.28 & 28.37 \\
\hline
\end{tabular}

Mean of Score (\%)

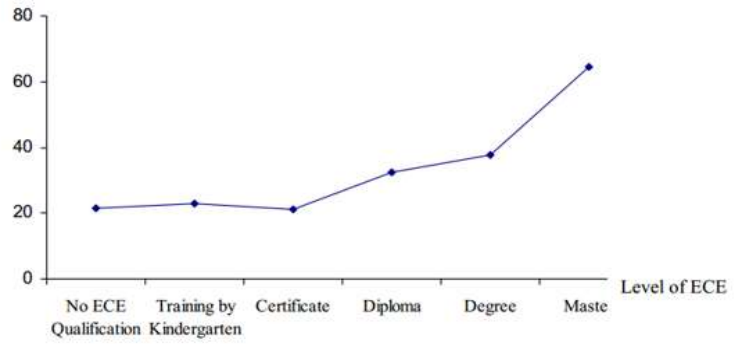

Fig 3. Mean \% of Participants' Score in Identifying Characteristic of LD by ECE Level

ix) A significant difference between teachers' ability to identify children at risk of different years of teaching experience. Null hypothesis $(\mathrm{Ho})$ state that, there is no significant difference between teachers' ability to identify children at risk of different years of teaching experience. One-way ANOVA was used to test this hypothesis. The independent variable, years of teaching experience range from $0-2$ years, 3-5 years, 6-8 years and above 9 years. The dependent variable was the total scores of teachers' ability to correctly identify the characteristic of children at risk of learning disabilities. The results of the ANOVA revealed no significant differences, $F(3,86)=$ $.817, \mathrm{p}=.488$ as shown in Table 11 .

Table 11:

One-Way ANOVA Test Comparing Teachers' Ability to Identify Children at Risk of Learning Disabilities of Different Years of Teaching Experience

\begin{tabular}{llllll}
\hline & $\begin{array}{l}\text { Sum of } \\
\text { Squares }\end{array}$ & df & $\begin{array}{l}\text { Means } \\
\text { Square }\end{array}$ & F & Sig. \\
\hline $\begin{array}{l}\text { Between } \\
\text { group }\end{array}$ & 1984.62 & 3 & 661.54 & .817 & .488 \\
Within group & 69629.44 & 86 & 809.65 & & \\
Total & 71614.06 & 89 & & &
\end{tabular}

Preschool teachers of different educational attainment $(\mathrm{M}=27.28, \mathrm{SD}$ $=28.37)$ do not differ significantly in their ability to identify the characteristics of learning disability as shown in Figure 4. While Table 12 presents the information on means as well as standard deviation of the analysis.

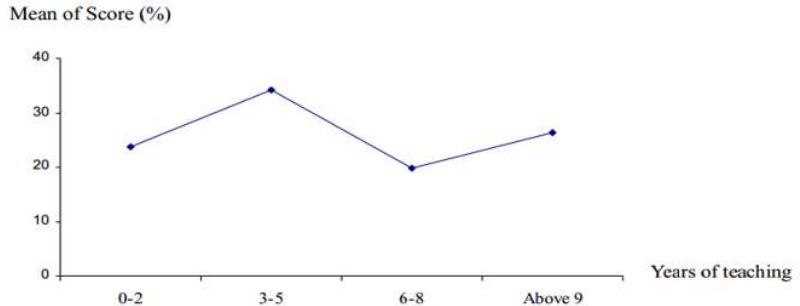

Fig. 4. Mean percentage of participant score incorrectly identifying characteristic of LD based on the years of teaching experience.

Table 12:

Means and Standard Deviations comparing Preschool Teachers' Ability in Identifying Children at Risk of $L D$ based on different years of teaching experience

\begin{tabular}{llll}
\hline Years of Teaching & $\mathbf{N}$ & Mean & SD \\
\hline $0-2$ & 20 & 23.65 & 27.84 \\
$3-5$ & 25 & 34.20 & 31.40 \\
$6-8$ & 9 & 19.89 & 20.40 \\
Above 9 & 36 & 26.33 & 28.24 \\
Total & 90 & 27.28 & 28.37 \\
\hline
\end{tabular}

\section{Discussion}

\section{Teachers' Competency Level in Identifying Children at Risk} of an LD

The findings reveal that majority participants of the study scored less than or equal to 20 marks (out of 100) for the questionnaire. From the findings, it was found that as many as $47 \%$ of the participants scored between 0 -20 marks while another $19 \%$ of participants (17 participants) scored only 21-40 marks. This points to the researcher that the current kindergarten teachers lack the competency to detect a child at risk of LD.

These findings are similar to Sawhney and Bansal (2018), and Kafonogo and Bali (2013). Sawhney and Basal (2018) stated the teachers in their study had limited knowledge regarding LD. Meanwhile, Kafonogo and Bali (2013) in their study state only a few teachers had awareness of students with LD in their class. However, this study contradicts Alahmadi and El-Keshky (2018) findings which showed their teachers had average knowledge regarding LD.

These findings also match statements made by the then Malaysian Deputy Education Minister in 2016, which stated that some teachers lacked the know-how to help children with learning disabilities. The statement also corresponds to the information provided by President of Pertubuhan Sokongan Ibubapa Dyslexia Malaysia (PSIDM), which stated that there are more national schools' teachers that needed to be trained so they will be able to recognize the symptoms of learning disability (Mariswanie, 2018).

\section{The Relationship of Teachers' Education Level and Their Competency in Identifying Students at Risk of LD}

Research hypothesis stated that there would be no significant relationship between teachers' general education level and ability to identify children at risk. However, analysis of data revealed that there was a significant relationship between teacher general education level and their ability to identify children at risk. The findings indicated that 
teacher who had higher general education level tend to display higher ability to identify children at risk of an LD.

For the relationship between different ECE educational attainments and teachers' ability to identify children at risk, null hypothesis (Ho) stated that there will be no significant difference. However, one-way analysis of variance (ANOVA) that was conducted showed an otherwise different results. It was found there are significant differences between teachers' ability to identify children at risk and different ECE educational attainments.

The findings of this study are parallel to research carried out by Alahmadi and El Keshky (2019), Shari and Vranda (2015) and Kakabaree, Arjmandnia and Afrooz (2012). However, it does contradict with Khalil and Jenahi (2019) research. The findings of the study, as the researchers suggested, could be due to the lack of pre-and post-graduate training for teachers on generally learning about disabilities, before narrowing down on ADHD in particular.

\section{The Relationship of Teachers' Work Experience and Their Competency in Identifying Students at Risk of LD.}

The final null hypothesis states that there will be no significant difference between years of teaching experience and teachers' competency in identifying students with LD. The statistical investigation by One-way ANOVA proved this to be true. The finding reveals that statistically, there is no significant difference between teachers' ability to identify children at risk and the different years of teaching experience for the preschool teachers.

Thus, this study shows that teachers who were more experience do not necessarily have the ability to identify children at risk. It also shows that teachers' teaching experience may not necessarily reflect the teachers' knowledge in identifying children at risk.

The findings of this study are aligned to Leite (2012) and Siderides, Antoniou, and Padeliadadu (2008) research which focused on teachers' ability on knowledge and detection of students with LD. However, the findings do contradict with Tsakiridou and Polyzopoulou (2014) research, which the results show that teaching experience is a significant variable. They further explain that the teachers' prior teaching experience offers the educators a greater sense of overall effectiveness, a sense of efficacy in classroom management and are successful in the use of educational strategies.

\section{Conclusion}

Teachers from this study are revealed to be lacking competency in identifying children that are at risk of LD. This is indicated by poor scoring of the questionnaire by the participants in whereby as many as $47 \%$ of the participants only scored 20 marks out of the full 100 . Besides that, the findings reveal that there is a significant difference and a positive correlation between teachers' qualification and their ability to identify students at risks of a learning disability. Lastly, the findings show that there is no significant difference between teachers' duration of teaching experience and their ability to identify a child at risk of an $\mathrm{LD}$

According to Professor Datuk Dr Norazah Mohd Nordin, dean of the Faculty of Education, Universiti Kebangsaan Malaysia (UKM), the MOE of Malaysia has set the target of $75 \%$ of special needs students attending school by 2025 , hence increasing the need for an increased number of schools with special education programmes (Rozana, 2018). In a nutshell, the increased number of schools would also require the number of skilled and trained early childhood teachers with expertise in LD to be consequently increased as well.
Therefore, this research has a significant impact on the inclusivity debates and concerns surrounding young children with LD. The findings have revealed that the current teachers lack competence in identifying children at risks of LD and discussed the relationship of variables such as academic qualifications and duration of teaching experience of teachers in identifying young preschool children with LD.

While this research has provided some insight of Malaysian private teachers' competency on their ability to recognize children with learning disabilities, there is still much to study about competency of teachers for young children with LD in the hopes of increasing the number education facilities that are able to cater for learning disabled young children.

Finally, more importantly, it provides insights which will aid young children with LD, early education (preschool) teachers, parents, and policymakers, towards an education system that is more inclusive in the future.

\section{References}

Abdul Nasir, Alfa Nur Aini Erman Efendi. (2016).Special education for children with disabilities in Malaysia: Progress and obstacles. Malaysian Journal of Society and Space, 12 (10), 78 - 87.

Black, H. \& Wolf, A. (1990). Knowledge and Competence. London: HMSO.

Cavazos, L. F. (2002). Emphasizing Performance Goals and High-Quality Education for All Students. Phi Delta Kappan, 83(9), 690-697.

Cheng, M. M-H., \& Cheung, W-M. (2004). Comparing perceptions: The competence of novice teachers and the expectations of school principals, Asia Pacific Education Review, 5(2), 188-199.

El-Keshky, Mogeda \& Alahmadi, Nsreen. (2018). Assessing primary school teachers's knowledge of specific learning disabilities in the Kingdom of Saudi Arabia. Journal of Educational and Developmental Psychology. 9(1), 9-22

Fraenkel, J. \& Wallen, N. (2011).. How to design and evaluate research in education (6th ed.). New York, NY: McGraw-Hill.

Tsakiridou, H. \& Polyzopoulou, K. (2014). Greek teachers' attitudes toward the inclusion of students with special educational needs. American Journal of Educational Research, 2(4), 208-218.

Hammill, D., Leigh, J., McNutt, G. \& Larsen, S. (1987). A new definition of learning disabilities. Learning Disability Quarterly, 4, 336-342.

Hebbeler, K \& Spiker, D. (2016). Supporting young children with disabilities. Future of Children. 26, 185-206.

Hodkinson, P. (1992), Alternative models of competence in vocational education and training, Journal of Further and Higher Education, 16(2), 30-39.

Kafonogo, F. M and Bali, T. A. L. (2013) Kafonogo F M Exploring classroom teachers' awareness of pupils with learning disabilities: Focusing on public primary schools in Tanzania. Journal of Education and Practice, 4(24), 58-66

Kakabaree, K. Arjomandnia, A. K \& Afrooz, G. (2012). The study of awareness and capability of primary school teachers in identifying students with learning disability in the province of Kermanshah. Procedia-Social and Behavioral Sciences, Volume 46, 2615-2619

Khalil, M. S. and Jenahi, E. (2019).How teachers' knowledge of attention deficit hyperactivity disorder makes difference in doctors' diagnostic decisions and management. Saudi Journal of Medicine and Medical Sciences, 3(2), 151-157.

Leite, S.. (2012). Dyslexia Through the Eyes of Primary School Teachers. 3rd International Conference on Education and Educational Psychology (ICEEPSY).

Ministry of Education Malaysia. (2013). Special education. http://jpwpkl.moe.gov.my/index.php/en/educationinformation/student/ 117-special-education

Ravassard, M. (2018). Persons with disabilities. Retrieved from https://www.right-to-education.org/issue-page/marginalisedgroups/persons-disabilities

Reynolds, M. \& Salters, M. (1995). Models of competence and teacher training, Cambridge Journal of Education, 25:3, pp. 349-359.

Santrock, J. W. (2006). Educational psychology. Classroom update: Preparing for PRAXISTM and practice (2nd ed.). New York: McGraw- 
Hill.

Sawhney, N \& Bansal, S. (2014). Study of awareness of learning disabilities among elementary school teachers. Conference: International Education Confer 'Education as a Right across the Levels: Challenges, Opportunities and Strategies, New Delhi.

Shari, M., \& Vranda, M. N. (2015). Knowledge of primary school teachers in identifying children with learning disabilities, Disability, $C B R$ and Inclusive Development, 26(3), 68-76.

Siderides, G. D., Antoniou, F. \& Padeliadu, S. (2008) .Teacher biases in the identification of learning disabilities: an application of the logistic multilevel model, Fall 2008 31, 199-209.

Singal, N., Salifu, E. M., Iddrisu, K., Casely-Hayford, L. \& Lundebye, H. (2015). The impact of education in shaping lives: reflections of young people with disabilities in Ghana. International Journal of Inclusive Education, 19, 908-925.
UNICEF. (2017). Childhood disability in Malaysia: A study of knowledge, attitudes and practices.

https://www.unicef.org/malaysia/Final_File_Childhood_Disability_in_Malaysi a Boo.

Erda Kursyiah Basir. (2016 April 10). Training teachers to handle special kids. The Star. Retrieved from

https://www.thestar.com.my/news/education/2016/04/10/training-teachers-tohandle-special-kids/

Arukesamy, K. (2017, June 19). Disability screening needed. The Sun. Retrieved from https://www.pressreader.com/

Rozana Sani. (2018 May 30). Inclusive education for people with different abilities. NewStraits Times. Retrieved from https://www.nst.com.my/education/2018/05/374698/inclusiveeducation-people-different-abilities 